Mahasiswa Milenial Berkarakter Santri...

\title{
MAHASISWA MILENIAL BERKARAKTER SANTRI (STUDI INSTITUTUT ZAINAUL HASAN GENGGONG PROBOLINGGO)
}

\author{
Nanang Qosim \\ Institutut Zainaul Hasan Genggong Probolinggo \\ qosimatik99@gmail.com \\ Abdul Hamid \\ Institutut Zainaul Hasan Genggong Probolinggo \\ abdulhamid81@gmail.com
}

\begin{abstract}
ABSTRAK:
Dewasa ini dalam dunia pendidikan, khususnya pendidikan yang ber "label" Islam dihadapkan pada tuntutan masyarakat yang menghendaki agar perguruan tinggi mampu menghasilkan output yang benar-benar berkualitas tinggi. Lulusan yang dikehendaki selain menguasai ilmu pengetahuan, skill, dan keterampilan yang dibutuhkan untuk kehidupan yang layak dan sejahtera, juga memiliki bekal pengetahuan agama, moral dan akhlak mulia, serta amal shaleh. Institute Zainul Hasan Genggong meupakan lembaga pendidikan tinggi yang berkarakter kepesantrenan. secara visioneri merupakan lembaga yang berkarakter kepesantrenan. Bertekad mencetak sosok intelektual yangmemiliki kedalaman spiritual, keagungan akhlak, keluasan ilmu, dan profesional. Penguasaan dimensi profan yang terwakili dengan penguasaan iptek, dan dimensi sacral yang diwakili iman dan taqwa adalah suatu yang tidak bisa ditawar lagi. Pesantren yang merupakan sub kultur dari pendidikan nasional secara budaya memiliki nilai-nilai yang kuat untuk bisa diartikulasikan melalui iklim organisasi perguruan tinggi. Oleh karenanya keberadaan pesantren menjadi partner yang ideal bagi pemerintah untuk bersama-sama meningkatkan mutu pendidikan sebagai basis bagi pelaksanaan transformasi sosial melalui penyediaan sumber daya manusia yang qualified dan berakhlakul karimah yang menekankan nilai-nilai religius moderat yang mencerminkan nilai Islam rahmatan lilalamin
\end{abstract}

Kata kunci: Millennial Students, Ethics and Santri

64 | FENOMENA, Vol.19 No.1April 2020 


\section{PENDAHULUAN}

Mahasiswa adalah orang yang menuntut ilmu di perguruan tinggi Negeri maupun swasta. Mahasiswa merupakan calon pemimpin (potential leaders) generasi masa depan. Mahasiswa perlu merubah mindset lebih baik, jiwa, kepribadian dan sosial serta kesehatan mental kuat. Seorang mahasiswa bisa mengatasi masalah-masalah sulit, selalu menanamkan positif thinking pada dirinya dan orang lain. Tidak mudah putus asa dalam menghdapai tantangn dan hambatan yang menerpa serta tidak mudah mengeluh pada keadaan dirinya.

Kedudukan mahasiswa memiliki posisi teristimewa di masyarakat terutama perannya menjadi agen perubahan (agent of change) dalam berbgai bidang. Ciri khas mahasiswa adalah berfikir kritis dan berfikir analisa sebelum melangkah. Meskipun hard skill atau nilai akademik unggul, melainkan soft skill lebih penting dalam sosialisasi, kolaborasi, dan komunikasi serta berkontribusi nyata.

Eskalasi radikalisme kian meluas, termasuk menyasar peserta didik. Penelitian Azyumardi Azra menyebutkan bahwa anak-anak sekolah hingga mahasiswa sedang menjadi target khusus rekrutmen kelompok radikalis dengan cara melakukan cuci otak terhadap pelajar dan diisi dengan ideologi radikal tertentu ${ }^{1}$. Komarudin Hidayat juga mengungkapkan bahwa gerakan dan jaringan radikalisme keagamaan telah menyusup ke lembaga pendidikan. ${ }^{2}$ Data kementeria agama 2019 menunujkan bahwa, perguruan tinggi juga menjadi saasaran empuk radikalisme. UI Jakarta, IPB, ITB, UGM Yogyakarta, UNY, Unibraw Malang, Unair, Unram, UIN Jakarta dan UIN Bandung, telah tertapapar radikalisme secara paham keagamaan. ${ }^{3}$

Data diatas tentunya buka hal yang menggembirakan. Kampus yang merupakan ujung tombak lembaga yang melahirkan intelektual yang berkarakter ke Indonesiaan, tetapi dalam kenyataan telah banyak melenceng dari nilai-nilai ke Indonesiaan. Ini merupakan pekerjaan rumah yang cukup besar perguruan tinggi yang merupakan ujung tombak gerakan intelektual

\footnotetext{
${ }^{1}$ Azyumardi Azra, "Rekrutmen Anak Sekolah." Kamis, 28 April 2011, artikel diakses 7 Januari 2017 dari http://www. uinjkt. ac.id/index. php/section-blog/28-artikel/1912-rekrutmen-anak-sekolah.html.

${ }^{2}$ Komaruddin Hidayat, "Radikalisme Islam Menyusup ke SMU", artikel diakses 28 Januari 2017 dari http://www. uinjkt.ac.id/index.php/category-table/1091-radikalisme-islammenyusup-ke-smu.html.

${ }^{3}$ https://balitbangdiklat.kemenag.go.id
}

FENOMENA, Vol.19 No.1April 2020 | 65 
tetapi dalam kenyataan banyak kecolongan dalam pertarungan ide dan gagasan. Oleh karenaya tidak sedikit perguruan tinggi yang melakukan terobosan dalam pembentukan karakter mahasiswa. Salahsatunya adalah pembangunan pondok/ma'had mahasiswa yang bertujuan untuk membangun iklim kemahasiswaan.

Institute Zainul Hasan Genggong meupakan lembaga pendidikan tinggi yang berkarakter kepesantrenan. secara visioneri merupakan lembaga yang berkarakter kepesantrenan. Bertekad mencetak sosok intelektual yangmemiliki kedalaman spiritual, keagungan akhlak, keluasan ilmu, dan profesional. Penguasaan dimensi profan yang terwakili dengan penguasaan iptek, dan dimensi sacral yang diwakili iman dan taqwa adalah suatu yang tidak bisa ditawar lagi. Pesantren yang merupakan sub kultur dari pendidikan nasional secara budaya memiliki nilai-nilai yang kuat untuk bisa diartikulasikan melalui iklim organisasi perguruan tinggi. Oleh karenanya keberadaan pesantren menjadi partner yang ideal bagi pemerintah untuk bersama-sama meningkatkan mutu pendidikan sebagai basis bagi pelaksanaan transformasi sosial melalui penyediaan sumber daya manusia yang qualified dan berakhlakul karimah yang menekankan nilai-nilai religius moderat yang mencerminkan nilai Islam rabmatan lilalamin.

Sebagaimana dawuh KH. Mohammad Hasan Mutawakkil Alallah yang selalu diutarakan dalam berbagai kegiatan yakni "Jadilah kalian Santri yang Intelektual dan Intelektual yang Santri, Berfikir Modernis dan berbati Sufistik".4. Menjadi pelajar, menjadi ilmuwan, cendekiawan, konsultan, guru, dokter yang santri, dll. Setiap aktifitas di orientasikan untuk mewujudkan mahasisa beretika ala santri supaya bisa jadi key person agar mempunyai keberagamaan inklusif dan penyejuk dunia, rahmatan lil alamin.

\section{PEMBAHASAN}

Mahasiswa dan Agen Perubahan

Mahasiswa merupakan seseorang yang sedang berproses mencari ilmu seluas mungkin dan sedang menjalani pendidikan padas sebuah perguruan tinggi Swasta maupun Negeri yang terdiri dari akademik, politeknik,

\footnotetext{
${ }^{4}$ Mengutip dawuh KH. Mohammad Hasan Mutawakkil Alallah, SH, MM ( Ketua Yayasan PP. Zainul Hasan Genggong Pronolinggo) pada saat event penting di Kampus INZAH Genggong Probolinggo.
}

66 | FENOMENA, Vol.19 No.1April 2020 


\section{Nanang Qosim, Abdul Hamid}

kesehatan, sekolah tinggi, institut dan universitas. ${ }^{5}$ Mahasiswa adalah individu yang sedang belajar ilmu ditingkat perguruan negeri maupun swasta. Mereka memiliki semangat belajar inggi, intelektualitas, kecerdasan berpikir dan perencanaan yang matang dalam bertindak. Berpikir kritis, responsif dan bergerak cepat, memiliki sosial tinggi dan tepat merupakan identitas diri mahasiswayang melekat pada dirinya. ${ }^{6}$

Mahasiswa memasuki tahap perkembangannya jika berumur 18 sampai 25 tahun. Ini merupakan tahapan masa remaja akhir sampai masa dewasa awal. Melihat segi perkembangan, tugas perkembangan mahasiswa ini adalah memantapakan pendirian hidup (jati diri). ${ }^{7}$

Mereka mendaftarkan diri dan terdaftar sebagai terpelajar di perguruan tinggi disebut mahasiswa. Terdaftar jadi seorang mahasiswa di Perguruan Tinggi merupakan syarat administrative saja, melainkan menjadi seorang mahasiswa memiliki arti yang lebih luas.

Memikul sebuah gelar sebagai mahasiswa adalah kebanggaan tersendiri sekaligus menjadi sebuah tantangan. Dalam ekspektasi dan pertanggung jawaban yang dipikul seorang mahasiswa sangatlah besar. Mahasiswa merupakan dinamisator perubahan-perubahan masyarakat menuju perkembangan dan perubahan (agent of change) lebih baik, memberikan solusi setiap masalah yang dihadapi masyarakat, bangsa dan Negara.

Peran dan Fungsi Mahasiswa

1) Peran moral (The moral role)

Setiap mahasiswa memiliki kebebasan memilih jalan kehidupan yang diinginkan. Jika seorang mahasiswa tidak mampu memberi contoh teladan baik berarti telah meninggalkan amanah dan tanggung jawab sebagai terpelajar. Kalau seorang mahasiswa masih tetap berorientasi kepada hedonisme (hura-hura, foya-foya dan kesenanggan belaka) berarti mmereka telah berada dalam kerugian besar. Apabila mahasiswa lebih tertarik mengisi waktu luang mereka dengan agenda rutinitas pacaran saja (dating routine), nongkrong (bangout), nge-gosip (gossiping) tanpa memperhatikan perubahanperubahan yang selalu up to date dan meng-up grade di negeri ini maka seyog-

\footnotetext{
${ }^{5}$ Hartaji, Damar A. Motivasi Berprestasi Pada Mahasiswa yang Berkuliah Dengan Jurusan Pilihan Orangtua. (Bandung: Fakultas Psikologi Universitas Gunadarma. 2012)

${ }^{6}$ Dwi Siswoyo, IImu Pendidikan. (Yogyakarta: UNY Press, 2007)

${ }^{7}$ Syamsu Yusuf, Psikologi Perkembangan Anak dan Remaja. (Bandung: Remaja Rosdakarya, 2012)
}

FENOMENA, Vol.19 No.1April 2020 | 67 
yanya merupakan generasi "gagal product" yaitu generasi yang terbuai, tenggelam dan mengabaikan terhadap tugas serta tanggung jawab sebagai mahasiswa (pemuda, terpelajar, berintelektual dan berwawasan luas).

2) Peran sosial (Social role)

Mahasiswa mampu menumbuh kembangkan jiwa solidaritas sosial. bertanggung jawab pada dirinya, tetapi juga harus membawa manfaat bagi mayarakat sekitar.

3) Peran intelektual (The role of intellectuals)

Mahasiswa merupakan insan sebagai calon sarjana yang terlibat di dalam perguruan tinggi khususnya Kampus Institut Ilmu Keislaman Zainul Hasan Genggong (manunggal dengan masyarakat), dididik, dibina serta harapan menjadi seorang yang berintelektual tinggi. Orang intelek harus mampu mewujudkan dalam ranah kehidupan nyata.

4) Peran Akademik (Academic Role)

Banyak aktivitas mahasiswa seperti; mengikuti program organisasi (Bem, Dema, Imapsi, Ormawa, Osmajur, HMPS dll), turun kejalan, turun ke rakyat dengan aksi sosialnya, sesisbuk apapun aktivitasnya jangan melupakan bahwa dirinya adalah insan akademik. Mahasiswa yang arif dan bijaksana tetap menjaga kuliahnya. Mereka ingin membanggakan orang tuanya, lulus kuliah tepat waktu dan berhasil.

Gelar (degree) disandang mahasiswa diantaranya : 1) Guardian of value (Menjaga nilai-nilai kebenaran mutlak masyarakat: kejujuran, keadilan, gotong royong, integritas, empati, simpati dll); 2) Direct of change (Pelaku perubahan langsung); 3) Agent of change (Agent perbahan); 3) Iron stock (Tidak pernah habis ); 4) Moral of force (Memiliki moral baik ); 5) Social of control Pengontrol kehidupan sosial).

\section{Perkembangan Mahasiswa dan Kekuatan Karakter Mandiri}

Ciri perkembangan remaja lanjut usia 18 sampai 21 tahun, yaitu: $\left.{ }^{8} 1\right)$ Menerima keadaan fisiknya (Accept his physical state); 2) Kebebasan emosional (Emotional freedom); 3) Mampu bergaul (Being able to get along); 4) Menemukan model untuk identifikasi (Find a model for identification); 5) Mengetahui kemampuan sendiri (Know self own abilities); 6) Menguasai diri atas dasar skala nilai dan norma (Mastering yourself on the basis of the scale of values and norms); 7)

\footnotetext{
${ }^{8}$ Singgih Gunarsa \& Yulia Gunarsa, Psikologi Praktis Anak, Remaja dan Keluarga. (Jakarta: Gunung Mulia, 2001)129-131
}

68 | FENOMENA, Vol.19 No.1April 2020 
Membuang aksi dan cara penyesuaian kekanak-kanakan (Throwing out actions and childish adjustments).

Pada masa Transisi melibatkan seluruh gerakan perubahahan menuju sebuah lembaga pendidikan lebih tinggi, lebih besar dan tidak individual, seperti interaksi sosial dengan kelompok segenerasi dari berbagai daerah yang beragam social culture. Lebih peduli dan memperhatikan dalam meningkatkan prestasi dan nilai akademik. ${ }^{9}$

\section{Tranformasi Karakter Santri di Kalangan Mahasiswa; Wujud Internal-} isasi

Pendapat C. C Berg mengenai asal muasal kata santri yaitu bahasa India, shastri, yaitu orang yang mengetahi dan memahami buku atau kitab suci agama Hindu. Sementara itu, mengenai istilah santri berasal dari Bahasa Tamil memurut H.John yaitu guru mengaji. ${ }^{1}$ Mahasiswa adalah julukan santri yang belajar mendalami ilmu agama di pesantren. ${ }^{1}$

Nurcholish Madjid berpendapat mengenai kata "santri", yaitu ; "Sastri" bahasa sanskerta yaitu melek huruf (membaca dan menulis). "Cantrike" berarti orang yang selalu aktif mengikuti segala aktifitas, mendampingi dan tinggal bersama guru. ${ }^{1}$

2

Santri adalah siswa atau mahasiswa yang terdidik, terpelajar, dan penggerak serta melanjutkan perjuangan ulama. Santri merupakan gelar kemuliaan, kehormatan, kebanggaan sebab orang memperoleh gelar Santri bukan karena sebagai pelajar/ mahasiswa melainkan memiliki akhlak atau budi pekerti yang tidak miliki orang awam pada umumnya. ${ }^{1}$

Budaya pesantren, masih memelihara system hubungan antara guru dan murid berlangsung sumur hidup baik bagi kyai maupun santri. Perasaan hormat dan kepatuhan murid kepadanya gurunya berlaku mutlak dan tidak putus. Seorang santri memutuskan hubungan dengan gurunya dianggap sebagai aib besar, dan berakibat hilangnya barokah dari guru dan ilmu penge-

\footnotetext{
${ }^{9}$ Santrock, John W, Life Span Development (Jakarta: Erlangga, 2002)74

1 Babun Suharto, Dari Pesantren Untuk Umat: Reiventing Eksistensi Pesantrendi Era Globalisasi (Surabaya: Imtiyaz, 2011 ).9

1 Efendi, Nur. Manajemen Perubahan Di Pondok Pesantren Konstruksi teoretik Dan Praktik Pengelolaan Perubahan Sebagai Upaya Pewarisan Tradisi Dan Menatap Tantangan Masa Depan. (Yogyakarta: Teras, 2014). 127

1 Yasmadi, Modernisasi Pesañtren: Kritik Nurcholish Madjid Terhadap Pendidikan Islam Tradisional ( Jakarta: Ciputat Press, 2005). 61

1 Abdul Qadir Jailani, Peran Ulåmma dan Santri (Surabaya: Bina IImu, 1994) 7-8
} 
tahuannya tidak manfaat. Bagi seorang santri adalah "tabu" mengatakan bahawa ia "bekas" murid dari seorang kyai tertentu. Sebab, sekali menjadi murid selamanya tetap jadi murid. Apabila sang guru sudah meninggal kita harus tetap menunjukkan rasa hormat dengan tidak melupakan kontak dengan pesantren guru. ${ }^{1}$

4

Hubungan ideal antara seorang guru dan murid tidak ada istilah "dia mantan guruku" atau sebaliknya "dia mantan muridku", selamanya tetap jadi guru dan selamnya jadi murid.

Seorang santri atau murid atau mahasiswa harus bisa melakukan halhal berikut, yaitu : ${ }^{1}$ 1) Selalu mengucapkan salam, 2) Mengembirakan hati gurunya; 3) Tidak boleh berjalan didepan sang guru; 3) Tidak membuka percakapan dulu sebelum sang guru memulai; 4) Berbicara dengan guru seperlunya; 5)Jangan bertanya jika hati guru belum mengizinkan.

Semua santri atau murid seharusnya menunjukkan rasa hormat dan tawadhu'nya kepada sang guru (dosen). Sebagai manifestasi dari penyerahan totalitas kepada sang guru yang dianggap otoritas, melainkan sebuah keyakinan seorang santri bahwa guru adalah penyalur rahmat Tuhan dan barokah. Di kawasan pesantren biasanya Kyai dan Santri, sedangkan dikawasan kampus antara Dosen dan Mahasiswa.

Semua stakeholder seharusnya sudah mengaplikasikan dan menjadi kebiasaan oleh semua mahasiswa Kampus Institut Ilmu Keislaman Zainul Hasan Genggong Probolinggo sebagai Kampus "Pelopor Khoiru Ummab".

\section{Hubungan Mahasiswa dengan Santri}

Mahasiswa yang Santri atau Santri yang Mahasiswa ${ }^{1}$, mengusahakan semua mahasiswa harus membiasakan mengamalkan dan mempertahankan amaliyah-amaliyah serta ajaran Ahlussunnah wal Jamaah dalam kehidupan sehari-hari. Sebagian besar mahasiswa Kampus Institut Ilmu Keislaman Zainul Hasan Genggong memiliki latar belakang pendidikan pesantren dan dari desa. Kampus perlu mewadahi amaliyahnya agar bisa diamalkan setiap saat. Amaliyah tersebut meliputi; shalawatan, yasinan, tahlilan, maulidan, hotmil qur'an, pembacaan rotib, manaqib sudah mumbudaya di lingkungan kampus.

1 Zamakhsyari Dhofier, Tradist Pesanren (studi Pandangan Hidup Kyai dan Visinya mengenai masa depan Indonesia. (Jakarta. LP3ES, anggota IKAPI, 2015) 125

1 Zamakhsyari Dhofier, 1265

1 Dawuh Hassan Ahsan Malik, (Salah satu Pengasuh PP. Zainul Hasan Genggong) pada saat acara PK2MB tahun akademik 2019/2020

70 | FENOMENA, Vol.19 No.1April 2020 


\section{Nanang Qosim, Abdul Hamid}

"Kuliah oke, nyantri oke, prestasi oke, bermartabat"1 Kalau melihat "santri mahasiswa" timbullah suatu pertanyaan, apakah mahasiswa santri harus kuliah dengan memakai sarung? Ataukah mahasiswi yang harus mengenakan cadar? mari kita berfikir reflektif sejenak, melihat makna, sifat dan syarat sebagai santri dan bagaimana seorang di sebut mahasiswa, jika di satukan memang akan ada perbedaan, pada dasarnya di demensi-dimensi yang berbeda dan biogenis yang berbeda pula. Apabila mahasiswa dan santri di kombinasi menjadi santri mahasiswa bukankah suatu yang luar biasa, dimana santri mahasiswa yang tetap menjadi mahasiswa dengan tanpa meninggalkan eksistensi kesantriannya juga menjadi santri tanpa mengabaikan kodratnya sebagai mahasiswa.

\section{KESIMPULAN}

Memikul gelar sebagai mahasiswa adalah kebanggaan tersendiri sekaligus menjadi sebuah tantangan. Dalam ekspektasi dan pertanggung jawaban yang dipikul seorang mahasiswa sangat besar. Mahasiswa merupakan dinamisator perubahan masyarakat menuju perkembangan dan perubahan (agent of change) lebih baik, memberikan solusi setiap masalah yang dihadapi masyarakat, bangsa dan Negara.

Mengenai masalah etika diatas menemukan titik terang bahwa etika merupakan dasar penilaian manusia manusia terhadap moralitas. Keberadaan etika berimplikasi pada penilaian benar atau tidaknya suatu tidakan atau perbuatan masyarakat. Namun etika tidak menghukumi suatu tindakan bermakna benar atau bermakna salah. Melainkan, etika hanya menyediakan dasardasar penilaian yang akan digunakan oleh moralitas untuk membenarkan atau menyalahkan suatu tindakan.

Santri adalah siswa atau mahasiswa yang terdidik, terpelajar, dan penggerak serta melanjutkan perjuangan ulama. Santri merupakan gelar kemuliaan, kehormatan, kebanggaan sebab orang memperoleh gelar Santri bukan karena sebagai pelajar/ mahasiswa melainkan memiliki akhlak atau budi pekerti yang tidak miliki orang awam pada umumnya.

Mahasiswa yang Santri atau Santri yang Mahasiswa, mengusahakan semua mahasiswa harus mengamalkan dan mempertahankan amaliyah-

1 Dawuh Gus Haris (Salah sat'u Pengasuh PP. Zainul Hasan Genggong) pada saat acara PK2MB tahun akademik 2019/2020

FENOMENA, Vol.19 No.1April 2020 | 71 
amaliyah serta ajaran Ahlussunnah wal Jamaah dalam kehidupan sehari-hari. "Kuliab oke, nyantri oke, prestasi oke, bermartabat"

\section{DAFTAR PUSTAKA}

Abdullah, Yatimin. Pengantar Studi Etika. (Jakarta: Raja Grafindo Persada, 2006)

Azra, Azyumardi, "Rekrutmen Anak Sekolah.” Kamis, 28 April 2011, artikel diakses 7 Januari 2017 dari http://www. uinjkt. ac.id/index. php/sectionblog/28-artikel/1912--rekrutmen-anak-sekolah.html.

Babun Suharto, Dari Pesantren Untuk Umat: Reiventing Eksistensi Pesantrendi Era Globalisasi (Surabaya: Imtiyaz, 2011 )

Dhofier, Zamakhsyari, Tradisi Pesanren (studi Pandangan Hidup Kyai dan Visinya mengenai masa depan Indonesia (Jakarta. LP3ES, anggota IKAPI, 2015)

Gunarsa, Singgih \& Gunarsa, Yulia. Psikologi Praktis Anak, Remaja dan Keluarga. (Jakarta: Gunung Mulia, 2001)

Hartaji, Damar A. Motivasi Berprestasi Pada Mahasiswa yang Berkuliah Dengan Jurusan Pilihan Orangtua (Fakultas Psikologi Universitas Gunadarma, 2012)

Hidayat, Komaruddin, "Radikalisme Islam Menyusup ke SMU”, artikel diakses 28 Januari 2017 dari http://www. uinjkt.ac.id/index.php/categorytable/1091-radikalisme-islam-menyusup-ke-smu.html.

https://balitbangdiklat.kemenag.go.id

Jailani, Abdul Qadir, Peran Ulama dan Santri (Surabaya: Bina Ilmu, 1994)

Magnis, Franz, Suseno. Etika Dasar Masalah Masalah Pokok Filsafat Moral. (Yogyakarta: Kanisius, 1987)

Magnis, Franz, SusenoEtika Jawa Sebuah Analisis Falsafi Tentang Kebijakan Hidup Jawa. (Jakarta:Gramedia,1996)

Magnis,Franz, Suseno. Etika Jawa Sebuah Analisis Falsafi Tentang Kebijakan Hidup Jawa. (Jakarta:Gramedia,1996)

O, Louis, Kattsoff. Pengantar Filsafat. (Yogyakarta: Tiara Wacana Yogyakarta,1996)

Santrock, John W. Life Span Development. (Jakarta: Erlangga, 2002)

Siswoyo, Dwi. Ilmu Pendidikan (Yogyakarta: UNY Press, 2007)

Yusuf, Syamsu. Psikologi Perkembangan Anak dan Remaja. (Bandung: Remaja Rosdakarya. 2012)

72 | FENOMENA, Vol.19 No.1April 2020 